\title{
Diagnostic Criteria of Dementia
}

\author{
Rémi W. Bouchard
}

\begin{abstract}
In the past two decades there has been a tremendous effort among clinicians and searchers to improve the diagnostic criteria of the dementias on the basis of the differential neurological and neuropsychological profiles. This was an obligatory requirement for clinical trials and the development of treatments. Over the years it became rapidly evident that the cohorts of patients in studies had some degree of heterogeneity, making it difficult to interpret the results of some studies, particularly in the vascular dementias and the mild cognitive impairment (MCI) group. For example, many sub-types of the vascular group were included in clinical trials, such as the cortical strokes, the lacunar states and the diffuse white matter disease cases, and some of the patients might have had also mixed pathology. In addition, the standard DSM IV criteria for dementia no longer represent our present knowledge of the clinical profile of some of the dementias such as vascular dementia (VaD) and fronto-temporal dementia where the memory impairment is not necessarily the first requirement. To improve the validity of clinical trials and eventually help developing more appropriate treatments, we revised the present diagnostic criteria and made recommendations for some changes in the context of the 2nd Canadian Conference on the Development of Antidementia Therapies, held in 2004 and reviewed in the light of the recent literature as of early 2006 . It is expected that in the near future, these dementia criteria for clinical trials will have to be revised again in order to include specific subtypes of the dementias as well as biomarkers, structural and functional imaging.
\end{abstract}

RÉSUMÉ: Critères diagnostiques de la démence. Au cours des deux dernières décades, les cliniciens et chercheurs ont fait beaucoup de travail pour améliorer les critères diagnostiques des démences sur la base d'une meilleure connaissance des profils neurologiques et neuropsychologiques. Cela était nécessaire pour les essais cliniques et le développement de nouveaux traitements. Au cours des années il est devenu évident que les patients dans les protocoles de recherche avaient un certain degré d'hétérogénéité qui rendait difficile parfois l'interprétation de certains résultats notamment dans les démences vasculaires et les déficits cognitifs légers. Par exemple dans les études vasculaires, différents sous-groupes étaient inclus dans les études, comme les accidents vasculaires corticaux, les états lacunaires et les atteintes diffuses de la substance blanche et en plus certains des patients pouvaient aussi avoir des pathologies mixtes. De plus les critères classiques de démence selon le DSM IV ne correspondent plus au profil qu'on connaît maintenant des démences vasculaires et des démences fronto-temporales où la mémoire n'est pas nécessairement le premier critère obligatoire. Dans le but d'améliorer la validité des résultats des essais cliniques et éventuellement de développer des traitements appropriés, nous avons révisé les critères actuels des différentes démences et avons recommandé des modifications dans certains critères diagnostiques dans le cadre de la 2e Conférence Canadienne sur le Développement des Traitements de la Démence, tenue en 2004, et également à la lumière de la littérature récente jusqu'à début 2006. Dans un futur non lointain il faut s'attendre à ce que ces critères de démence pour des fins de recherche et d'essai clinique soient à nouveau révisés pour inclure les sous-groupes cliniques, les marqueurs biologiques ainsi que les données d'imagerie structurale et fonctionnelle.

Can. J. Neurol. Sci. 2007; 34: Suppl. 1 - S11-18

In the past two decades there has been a tremendous effort to improve the diagnostic criteria of the dementias on the basis of the differential neurological and neuropsychological profiles. This paper will review some of the progress and issues that remain around diagnostic criteria and, particularly, their application in developing therapeutics.

Dementia can be defined as a clinical syndrome of cognitive and functional decline, frequently associated with behaviour or personality changes. This is a clinical diagnosis that cannot be replaced by any laboratory or imaging test. Generally, the diagnosis is based on a careful history with a semi-structured interview and a detailed medical and neurological examination as well as some neuro-cognitive testing. Neuroimaging is recommended in clinical trials for the development of antidementia drugs, for selecting more homogeneous cohorts particularly in clinical subgroups such as vascular patients. Imaging is also recommended to rule out unsuspected lesions and for volumetric measurement in specific dementia syndromes and clinical trials.
Some conditions confound the diagnosis of dementia as described in the last Canadian consensus conference on the assessment of dementia: ${ }^{1}$ sensory disorders, pre-existing psychotic symptoms, aphasia/dysarthria, language incompatibility patient/physician, mental retardation and any combination of these symptoms. Other conditions may also confound the diagnosis of dementia such as transient global amnesia, sub-clinical epileptic syndrome and overuse of

From the Clinique de mémoire et unité de recherche Alzheimer, CHA Hôpital de l'Enfant-Jésus, Québec, QC, Canada.

ReCEIVED OCTOBER 7, 2005. ACCEPTEd In FinAl FORM July 18, 2006. Reprint requests to: Rémi W. Bouchard, Clinique de mémoire et unité de recherche Alzheimer, CHA Hôpital de l'Enfant-Jésus, 1401, 18e rue, Québec, Québec, G1J 1Z4, Canada. 
sedative. Most of these conditions, often referred to memory clinics for evaluation, are not necessarily a manifestation of an early dementia syndrome but the clinician has to be very alert when evaluating such patients with cognitive complaints before they be considered for a clinical trial of antidementia therapy.

The clinical data are the basis for the differential diagnosis of dementias and are the key for the best accurate diagnosis prior to enrolment in any drug trial. For example, a progressive dementia syndrome without significant medical illness and no significant focal neurological deficit is more likely to be related to a degenerative disease and a sudden onset of cognitive deficit associated with any focal neurological deficit in a patient with vascular risk factors is likely to be a vascular-related cognitive deficit although progressive cognitive decline can be seen in vascular disease, particularly in deep white matter disease.

\section{GENERAL CRITERIA FOR DEMENTIA}

The standard criteria widely used for dementia have generally been those of the DSM IIIR ${ }^{2}$ and the DSM IV. ${ }^{3}$ The DSM IV criteria (and the most recent version the DSM-IV-TR ${ }^{4}$ ) require impairment of memory and at least one of the following domains: language, praxis, gnosis, executive functioning; there is impairment of social or professional life compared to the previous level of functioning and the decline does not occur only during delirium and cannot be explained by any other medical, neurological or psychiatric condition.

Over the years, it has become apparent that these criteria do not apply well to the spectrum of dementias. In Frontotemporal dementias as well as in vascular dementias, the memory deficit may not be the major complaint. In the context of clinical trials and in the development of new treatment, the memory impairment (which is present most of the time) should not be considered an obligatory requirement provided that at least two cognitive domains are impaired, and the other criteria are met. This approach away from a mandatory memory impairment has been validated in large cohorts of patients with dementia, where the diagnosis was based on the impairment of two cognitive domains with neuropsychological test support. ${ }^{5}$

The standard DSM criteria do not include specification around neuropsychiatric symptoms. This likely underestimates the importance of the psychiatric manifestations such as mood and behaviour changes or psychotic features which may develop after or at the time of the cognitive decline or even precede by a few years the diagnosis of dementia. ${ }^{6}$ Particularly, a new onset of depression in the elderly should raise the possibility of an underlying dementing process, particularly in patients with a higher level of education. ${ }^{7}$ These features should be part of the diagnostic criteria of dementia as supportive features and should not exclude patients from antidementia drug trials if the other criteria of dementia are met. Furthermore, in the populationbased study of the Cardiovascular Health Study (CHS), neuropsychiatric manifestations have been found to be very common in the course of dementia, up to $75 \% .^{8}$

Since no set of diagnostic criteria is perfect, for research, clinical trials and development of new therapies, the DSM IV$\mathrm{TR}^{4}$ criteria for the diagnosis of dementia are recommended ${ }^{9}$ but with some of the above changes reflecting the present knowledge of the cognitive and psychiatric aspects of dementia, as outlined in Appendix A.

\section{Diagnostic Criteria for Alzheimer Disease (AD)}

The clinical data obtained from the careful clinical evaluation as described above are generally precise enough for an accurate diagnosis of the most common types of dementia for clinical trials. The standard criteria of the DSM IV ${ }^{3}$ (now the DSM-IV$\mathrm{TR}^{4}$ ) for $\mathrm{AD}$ have been used for research and in clinical trials and are still recommended (the same as the standard criteria for dementia together with the notion of insidious onset and progressive decline), since memory is a predominant symptom in $\mathrm{AD}$; however it should be specified that a more rapid onset and periods of relative stability do not exclude the diagnosis of AD. Mood and behaviour disturbances and psychotic features are added as supportive features, as outlined in the recommendation for the diagnosis of dementia (Appendix A). The criteria for probable AD of The National Institute of Neurological and Communicative Disorders and Stroke-Alzheimer's Disease and Related Disorders Work Group (NINCDS-ADRDA) have also been used for research purposes worldwide. The classic criteria have a high degree of accuracy of $\pm 90 \%,{ }^{9,11-13}$ which is better than any clinical biomarker at this date. They are summarized as follows: dementia based on clinical examination and neuropsychological tests, with onset between ages 40 and 90, deficits in two or more areas of cognition, progressive worsening of memory and other cognitive functions, normal consciousness; supportive features include progressive deterioration of language, praxis and gnosis, impaired ADL and behaviour, positive family history, normal CSF, non specific EEG, and progressive cerebral atrophy with time on neuroimaging. Other possible features include some plateaus in the course, seizures in late stages, and some neuropsychiatric and extrapyramidal symptoms, and normal CT or MRI for age. Some of these features are not part of the basic investigation for the diagnosis of dementia (e.g., CSF study, EEG recording) but are suitable in the context of specific research programs and the development of future therapies. Normal CT or MRI for age should be clarified the following way: normal CT or MRI for age do not exclude the diagnosis of AD, particularly in the early stages of the disease, although volumetric measurement of the hippocampal region with MRI may show some atrophy in the early stage of AD (Appendix A).

Both sets of criteria are acceptable for research and clinical trials at this time but they target the pure $\mathrm{AD}$ patients even if many of those $\mathrm{AD}$ patients have mixed pathologies. ${ }^{14}$ Also, these criteria do not include the very early stages of AD. Other criteria will have to be defined for these cohorts in future clinical trials. The DSM-IV-TR ${ }^{4}$ appears simpler to apply for the clinician but the NINCDS-ADRDA ${ }^{10}$ criteria are more suitable for research and clinical trials. Clinico-pathological correlation is not available for the modified version of the DSM-IV-TR ${ }^{4}$ for dementia and AD but, on clinical grounds, this version is likely to be as accurate as or better than the classic one.

\section{OTHER DEGENERATIVE DEMENTIAS}

Diagnostic criteria for Frontotemporal dementia (FTD) and Frontotemporal lobar dementia (FTLD)

Frontotemporal lobar dementia ${ }^{13}$ or Pick's complex ${ }^{15}$ are terms that have emerged to define a group of dementias including frontal dementia behaviour variant, primary 
progressive aphasia, semantic aphasia and frontal dementia with motor neuron disease. Corticobasal degeneration and progressive supranuclear palsy are included in some classification on the basis of their tauopathies. The prevalence of FTLD is difficult to assess as this condition may be underdiagnosed due to early psychiatric manifestations and few or no memory problems at the onset. For research protocols, the Lund and Manchester criteria ${ }^{16,17}$ have been widely used as well as the criteria of Neary et $\mathrm{al}^{13}$ and more recently of McKhann et al. ${ }^{18}$

The criteria of Neary et $\mathrm{al}^{13}$ include as core features: insidious onset and gradual progression, early impairment in social and personal conduct, early emotional blunting and loss of insight; supportive features include examples of behavioural changes, speech and language impairment, primitive reflexes and extrapyramidal signs, predominant atrophy in the frontal and/or temporal region on imaging and frontal lobe abnormalities on neuropsychological testing and memory, spatial orientation and perception which are not severely impaired, which is very important for the differential diagnosis. The first criteria could however better target changes in character and personality although it is described in the general introduction of the clinical profile. At present, the criteria of Neary et $\mathrm{al}^{13}$ are recommended for the diagnosis of FTLD in clinical trials. (Appendix A)

The criteria of McKhann et $\mathrm{al}^{18}$ for FTD describe as core features mainly personality and behavioural changes and language disturbances but address very little of the other aspects of cognitive function. We would recommend that the relative preservation of memory, spatial orientation and perception should be included in these core features, labelled as follows: "No severe impairment of memory, spatial orientation and perception at the onset", to be added after behaviour and language disturbances, as item 1.c (Appendix A). The other criteria are modulated on the DSM-IV-TR ${ }^{4}$ approach and remain unchanged. Considering all the subtypes of FTLD, it might be anticipated that in the future there will be further development of specific diagnostic criteria for clinical trials for each subtype of this category of dementias. ${ }^{13,18-21}$

\section{Diagnostic Criteria for Dementia with Lewy Bodies (DLB)}

Dementia with Lewy Bodies is one of a few conditions in which dementia is associated with extrapyramidal features. The time when the dementia, the extrapyramidal syndrome development and the psychiatric features appear in the course of the disease, is the basis for the differential diagnosis of the dementias with Parkinsonism. There is no consensus regarding the delay between the onset of parkinsonian features in DLB and the appearance of cognitive deficit. The recent 2005 consensus on DLB recommends arbitrarily a one year delay between motor parkinsonism and dementia though this concept of delay is still evolving. ${ }^{22}$ Dementia with Lewy Bodies is considered the second most frequent degenerative disease causing dementia, though this statement is controversial. The prevalence is reported as being 5-20\% depending on the study population and setting. Patients may be misdiagnosed or under diagnosed compared to AD. ${ }^{23}$ These patients are referred to different specialized clinics, including movement disorders, memory, psychiatric, geriatric and neurovascular depending on the predominant feature at the onset.
The basic clinical core features of DLB have not significantly changed between the DLB consortium reports of 1996 and 1999 published by McKeith et $\mathrm{al}^{24,25}$ In a recent 2005 revision, ${ }^{22}$ the authors raised questions around the difficulty of appropriately characterizing and quantifying the fluctuation and the hallucinations with some suggestions for methods to improve clinical assessments. Compared to the previous reports on supportive features they recommend including some structural and functional brain imaging to support or suggest the diagnosis of DLB. Furthermore they have reclassified supportive features in two categories; "suggestive features" are based on the frequency of occurrence compared to other dementia syndromes and "supportive features" on the common occurrence but lower specificity. The "suggestive features" include REM sleep behaviour disorder (association with synucleiopathy), severe neuroleptic sensitivity and "low dopamine transporter (DAT) uptake in basal ganglia" on functional imaging. The authors offer a new perspective that the presence of a single suggestive feature in the absence of any of the core features be considered sufficient for the diagnosis of "possible DLB". Remaining supportive features include myocardial scintigraphy and EEG.

These revised 2005 DLB criteria are a step forward to better define DLB and hopefully improve diagnostic sensitivity. This is important for the development of new therapies because these criteria are likely to improve the homogeneity of the cohorts. We recommend these recent criteria of $\mathrm{DLB}^{22}$ for research programs and future clinical trials (Appendix A). They will likely be most applicable in selected specialized centers offering specific imaging and, in clinical trials, such imaging studies would require standardized interpretation in the context of a central reading set-up.

\section{Diagnostic Criteria for Parkinsonian dementia}

Dementia associated with Parkinson's disease (PDD) is now considered as more prevalent than has been recognized in the past. Unfortunately, there are no validated standard clinical or research criteria for the diagnosis of PDD which currently hinges on the later development of dementia in a patient with Parkinson's disease. The cognitive profile and the time when the extrapyramidal syndrome appears are important in this the differential diagnosis. Early bilateral extrapyramidal symptoms (without predominance of tremor) associated with early cognitive decline and behaviour problem would favour DLB. Classic PD with unilateral symptoms at the onset and which is present for a few years before the appearance of cognitive decline would favour PDD, although there is no consensus on the number of years required. Based on the arbitrary one-year window for DLB criteria, ${ }^{22,38}$ a delay beyond one year would suggest PDD. This statement is not clear cut since, in most cases, the parkinsonian syndrome has been present for many years before the dementia becomes apparent. On the other hand, some cognitive decline has been documented well before the definite diagnosis of dementia in early PD. ${ }^{23,39}$ It may be difficult to draw a strict line between DLB and PDD when the delay parkinsonian features-cognitive deficit is short in these two diseases with a neuropathological continuum.

Dementia is frequent in advanced PD, ${ }^{26}$ and with age. ${ }^{27}$ The overall prevalence of dementia in PD ranges between nearly $30 \%$ 
in a community-based study ${ }^{28,29}$ to about $40 \% .^{30}$ In an older clinicopathological study, up to $45 \%$ of patients with PDD have been shown to have some Alzheimer pathology ${ }^{31}$ while more recent studies have identified more predominant synucleinopathy with the dementia. ${ }^{32,33}$ It is now well known in degenerative diseases that mixed pathology is not uncommon, e.g., $\mathrm{AD}$ and vascular contribution, ${ }^{34,35} \mathrm{AD}$ and $\mathrm{DLB},{ }^{36} \mathrm{AD}, \mathrm{PD}$ and features of DLB. ${ }^{37}$ In clinical trials the DSM IV ${ }^{4}$ criteria for PDD have been used. For the purpose of developing new treatment of PDD, this grey area of one to three years window should be avoided to make sure of the disease being targeted. For this reason and until new validated criteria are developed for PDD or under the general term DLB, the following criterion is recommended for clinical trials in PDD patients: "a well established diagnosis of PD for at least a few years before the onset of cognitive decline". The main other features of PDD include attention deficits, fluctuation, memory retrieval problems, impaired executive functions, ${ }^{26,30}$ impaired verbal fluency and personality changes. ${ }^{30,40,41}$ Contrary to DLB and $\mathrm{PDD}$, the extrapyramidal syndrome in $\mathrm{AD}$, mainly bradykinesia and rigidity, rarely tremor, occurs late in the course, is usually bilateral. This issue should not raise difficulties when selecting patients for trials in PDD.

\section{Diagnostic CRiteria for VASCUlaR DEMENTia (VAD)}

Dementia secondary to cerebrovascular pathology is called vascular dementia (VaD). Over the years, $\mathrm{VaD}$ has been considered the second most common cause of dementia. Initially, the diagnostic criteria were based on the clinical experience of experts but did not necessarily correlate with the pathology. With time, all criteria used have been studied with regards to their specificity and sensitivity compared to neuropathology. None is perfect. Vascular lesions were found in many of the dementia patients, including $\mathrm{AD}$ patients and, on the other hand, pure vascular pathology as the unique cause of dementia has been found quite rarely in some studies, as low as $10 \% .^{9,11}$ The majority of the patients seem to have mixed pathology, such as $\mathrm{AD}$ and vascular and sometimes Lewy bodies. ${ }^{34-37}$

Vascular dementia is a difficult diagnosis to make because of the frequent overlap with other diseases such as $\mathrm{AD}$, the absence of stroke history in some cases in the presence of a positive imaging ${ }^{42,43}$ and vice-versa. The concept of cognitive decline of vascular origin is an evolving concept. Many cerebral vascular lesions can cause some cognitive impairment but not necessarily dementia. The term vascular cognitive impairment $(\mathrm{VCI})^{44,45}$ is used as a general term that encompasses vascular MCI as well as $\mathrm{VaD}$ and can relate to any vascular brain pathologies. There is also a small clinical margin between VCI without dementia and true dementia. This is due to the subjective interpretation of the degree of interference in daily life or work; one could argue that $\mathrm{VaD}$ is an inappropriate term and that all patients have VCI at different degrees, and consequently new specific criteria for VCI should be developed. Other authors have suggested the term vascular cognitive disorder $(\mathrm{VCD})^{46,47}$ as a global diagnostic category including all cognitive decline of vascular origin except isolated deficits. Since the term dementia, according to the usual classic criteria, includes memory impairment as an obligatory symptom and since it does not apply to all vascular patients (and to some other dementias, as well, at the onset), depending on the site of the lesions, we suggest either the term dementia be redefined (e.g. modified version of the DS M-IV-TR ${ }^{4}$ for dementia) or the term $\mathrm{VaD}$ changed for the general term VCI with different degrees, including dementia. For drug trials, we recommend the modified definition of dementia of the DSM-IV$\mathrm{TR}^{4}$ to be part of the criteria for the vascular group.

Vascular dementia covers a large span of diseases with heterogeneous manifestations of vascular origin, depending on the site of the lesions, the number of lesions, the degree of impairment of the subcortical structures, etc. For this reason, the diagnostic criteria could be general or specific to each entity. Up to now, the criteria have been rather general and this explains why the concordance between the sets of criteria is very variable. ${ }^{43}$ It is possible also that this heterogeneity explains, at least partially, the difficulties encountered in clinical trials to demonstrate the efficacy of new treatments. At this time we recommend the general criteria of $\mathrm{VaD}$ but validated specific criteria for each sub-group would be more homogeneous (e.g. criteria for cortical multi-infarct dementia (MID), sub-cortical diffuse, lacunar state, etc.) and more suitable for the development of new therapies. The trend is obvious for defining the criteria by subgroups, considering the multiples aetiologies and the recent literature supporting this trend. ${ }^{48-50}$

There are at least four sets of criteria for the diagnosis of vascular dementia, and the degree of specificity and sensitivity is variable according to the set of criteria. None of them is perfect because of the heterogeneity of the aetiologies, the sites involved and the diversity of the symptoms: the The International Classification of Diseases, 10th revision (ICD10) $)^{51}$ the ADDTC of the State of California, ${ }^{52}$ the NINDS-AIREN ${ }^{53}$ and the DSM IV. ${ }^{3}$ These last two have been widely used for research protocols and clinical trials. In the CHS study using three different criteria (ADDTC, DSM IV, NINDS-AIREN) there has been discrepancies in the frequency of $\mathrm{VaD}$ among the diagnostic criteria, ${ }^{43}$ raising many questions regarding the existence or not of a stroke history, ${ }^{42}$ focal deficit, sudden onset or slowly progressive decline, clear relationship between vascular disease and cognitive decline, etc. In this study, ${ }^{43}$ none of the criteria has identified the same group of patients with $\mathrm{VaD}$. This reinforces the need for improving the diagnostic criteria, particularly for clinical trials and eventual treatment.

In addition of these sets of criteria, the modified version of the Hachinski ischemic scale ${ }^{54}$ is useful to support the vascular contribution in a dementia syndrome based on the vascular risk factor hypertension and the presence of symptoms and signs of cerebral vascular disease.

The NINDS-AIREN criteria $^{53}$ for $\mathrm{VaD}$ are recommended, with some changes: The first item should be "dementia as defined by the modified version of the DSM-IV-TR ${ }^{4}$ ", because memory is not a "must"; In section 2, cerebral vascular disease is defined by the presence of focal signs on neurological examination; this is not always present, since more diffuse neurological abnormality such as bradykinesia may be present in deep white matter lesions, without true focal deficit and this should be specified. Section 3 describes the relationship between dementia and vascular disease: the onset of dementia within three months after a stroke, the abrupt deterioration or fluctuating or stepwise progression of cognitive deficits. This is a fair statement in most 
cases of strategic infarcts, multiple cortical infarcts and some lacunar states but does not apply to all cases and particularly to some cases of deep white matter disease where cognitive deterioration may be slowly progressive ${ }^{55,56}$ For this reason, in that section we recommend adding: "possible progressive deterioration particularly if predominantly deep white matter disease". In addition, this relationship dementia-vascular disease is not always evident and one can never be sure that there is not some AD component in the vascular patients. Thus the "relationship" should be "the presumed relationship". The supportive features include gait disturbances, urinary incontinence, personality changes and impaired executive functions; the possibility of psychotic features is added in these features. We believe that vascular risk factors are important supportive features and we recommend adding in that section "score $\geq 4$ " on the modified ischemic scale, ${ }^{54}$ rather than using this scale as a separate criterion for inclusion in therapeutic trials. These changes do not explain everything, e.g., they do not address the possible AD component and the fact that a clear relationship between vascular disease and cognitive decline is not always present. In this rapidly evolving domain of mixed pathology, these issues will have to be reconsidered again in the close future for clinical trials on the basis of neuropsychological differential profile and neuroimaging. Although these criteria are going to become more and more complex, they are more complete and suitable for research purposes and the development of therapeutic strategies (Appendix A).

The DSM-IV-TR 4 criteria for $\mathrm{VaD}$ show higher sensitivity, lower specificity, ${ }^{43,57}$ but are easier to recognize and to apply. Since memory impairment is not always present, the modified version of the DSM-IV-TR ${ }^{4}$ criteria for $\mathrm{VaD}$ is recommended, which includes changes in the first item recommended for dementia: "Impairment of memory and/or another predominant cognitive domain". In $\mathrm{VaD}$, mood and behaviour disturbances are common and we recommend adding these items as supportive features as in the general criteria for dementia. The relationship between the clinical picture and the neuroimaging leaves some place to the clinical judgment and those criteria are likely to include the subcortical (which may not have a clear stroke history and a sudden onset) as well as the cortical strokes and require either focal symptoms and signs or a positive imaging and does not require unequal cognitive deficit, which might be less suitable for research and the development of specific treatment.

\section{Diagnostic CRITERIA FOR MILD COGNITIVE IMPAIRMENT (MCI)}

There has been a tremendous amount of literature concerning MCI in the recent years. A number of descriptions have been proposed in the past to describe the cognitive decline in elderly patients who have not reached the level of dementia according to the usual criteria, such as Age associated memory impairment (AAMI) ${ }^{58}$ Cognitive impairment, not dementia (CIND), ${ }^{59}$ Age associated cognitive decline (AACD) ${ }^{60} \mathrm{~A}$ clinical review of the whole spectrum from normal to dementia has been recently published. ${ }^{61}$

There is a great interest in defining this transitional state between the normal and the demented patient, because the therapeutic goals are to treat the patients as early as possible. In a longitudinal study with a follow-up of eight years as part of the Cardiovascular Heart Study, neuropsychological testing revealed that patients who developed clinical AD had some cognitive changes well before the diagnosis was made. ${ }^{62}$ With the diseasemodifying drugs in the pipeline, identifying the preclinical stage of $\mathrm{AD}^{63}$ would be a new era in the field of therapy for $\mathrm{AD}$. Up to now the definition of MCI used in clinical trials was the one of Petersen et al, ${ }^{64}$ and consisted of memory complaints and mild memory deficits on testing, without impairment of other aspects of cognition and without impairment in ADL, and relative normal functioning, without the usual criteria for dementia. However, when carefully tested, these patients have more that only mild memory deficit. Most of them have mild impairment in multiple domains. There profile is more compatible with the concept of AACD ${ }^{60}$ which includes other deficits than memory. ${ }^{65}$ In fact impairment of multiple domains was reported in epidemiological studies as the most common presentation of MCI, ${ }^{65-67}$ contrary to the form of MCI with only memory impairment (the amnestic form of $\mathrm{MCI}^{68}$ ) that represented a small proportion of subjects with MCI. The rate of conversion of MCI to AD is in the range of $10-15 \%$ per year. ${ }^{69}$ Not all patients convert to $\mathrm{AD}$, and the objective is to identify those patients considered as being at a preclinical stage of $\mathrm{AD}$, the ones who are more likely to progress to $\mathrm{AD}$, like the amnestic MCI patients, compared to other subgroups. These patients are a target for the development of new therapies, particularly disease-modifying drugs.

But the main problem for the definition of MCI remains the lack of homogeneity of patients, which has made the clinical trials difficult and may explain the relative negative results in drug trials. This is supported by the findings of some heterogeneity in the neuropathologic features of amnestic patients who progressed to dementia. ${ }^{70,71}$ To improve the validity of future studies, inclusion criteria for drug trials could be based on the general criteria of MCI, as described below, and target specific clinical sub-types (e.g., the amnestic type of MCI), include structural and functional neuroimaging and aetiology, in order to better define the cohorts and hopefully the true pre-AD patients and identify the possible responders.

In our view, MCI should refer to a general cognitive state where there is a mild decline (of any aetiology) in memory or/and any other cognitive function, subjectively and objectively, but without significant impairment of functioning and not fulfilling the usual criteria of dementia. Since at the present time there is no definite consensus for the diagnosis criteria for MCI, for therapeutic trials these core features are recommended, as a modified version of the Petersen's criteria ${ }^{64,68}$ to which need to be added clinical subtypes, neuroimaging and aetiology as guidelines to develop more specific treatments (Appendix A).

\section{Appendix A}

Summary of the recommended diagnostic criteria of dementias for anti-dementia drug development (Main changes are in bold italic)

A. Diagnostic criteria for dementia: a modified version of the DSM - IV-TR, ${ }^{4}$ summarized as follows:

a. Impairment of memory and/or any another predominant cognitive domain

b. Impairment of at least one of the following domains, 
in addition to a.: Language, praxis, gnosis, executive functioning

c. Impairment of social or professional life compared to previous level of functioning

d. Not only during delirium and unexplained by any other medical, neurological or psychiatric condition.

e. Supportive features: New onset of mood, behaviour disturbances or psychotic features

B. Diagnostic criteria for AD:

I. The NINCDS-ADRDA criteria, ${ }^{10}$ unchanged, except in the section "other possible clinical features", "Normal CT or MRI for age" should be clarified the following way: Normal CT or MRI for age does not exclude the diagnosis of $A D$, particularly in the early stages, although volumetric measurement of the hippocampal region with MRI may show some atrophy in early $A D$.

II. A modified version of the DSM-IV-TR, ${ }^{4}$ summarized as follows:

Items a. (impairment of memory), b. (impairment of at least one of the following domains: language, praxis, gnosis, executive functioning), c. (impairment of social or professional life compared to the previous level of functioning) and e. (not only during delirium and unexplained by any other medical, neurological or psychiatric condition) are unchanged.

d. Gradual onset and continuing cognitive decline; however the following conditions do not exclude the diagnosis of $A D$ :

1. more rapid onset

2. periods of relative stability in the course

f. Supportive features: New onset of mood, behaviour disturbances or psychotic features

C. Diagnostic criteria for FTD and FTLD:

I. The criteria of Neary et $\mathbf{a l}^{\mathbf{1 3}}$ for FTLD, unchanged

II. The criteria of McKhann et al for $\mathbf{F T D}^{\mathbf{1 8}}$ with minor changes regarding the absence of some cognitive deficits at the onset, summarized as follows for the first item, the rest being unchanged:

1. The development of behavioural or cognitive deficits manifested by either

a. Early and progressive change in personality, or

b. Early and progressive change in language, and

c. No severe impairment of memory, spatial orientation and perception at the onset

D. Diagnostic criteria for DLB: the recent version of McKeith et al $^{22}$ unchanged

E. Diagnostic criteria for VaD: a modified version of the NINDS-AIREN criteria, ${ }^{53}$ summarized as follows:

\section{Dementia as defined in the modified version of the DSM-IV-TR}

2. Cerebrovascular disease, defined by the presence of abnormal neurological examination (e.g., focal deficit, non focal extrapyramidal features such as bradykinesia), consistent with vascular pathology (with or without history of stroke), and evidence of relevant CVD by brain imaging.

3. A presumed relationship between the above two disorders, manifested or inferred by the presence of one or more of the following:

1. Onset of dementia within three months following a recognized stroke;

2. Abrupt deterioration in cognitive functions; or fluctuating, stepwise progression of cognitive deficits.

3. Possible progressive deterioration if predominantly deep white matter disease

4. Supportive features:

1. Early gait disturbance

2. History of unsteadiness and frequent, unprovoked falls

3. Early urinary urgency or incontinence unexplained by urologic/gynaecologic disease

4. Personality, mood changes or psychotic features and other subcortical deficits including psychomotor retardation and impaired executive function

5. Score $\geq 4$ on the modified ischemic scale ${ }^{54}$

F. General diagnostic criteria for MCI: a modified version of the Petersen's criteria, ${ }^{64}$ summarized as follows:

A. Subjective complaint of memory impairment or/and of any other cognitive domain, particularly if noted by an informant

B. Mild objective deficits in the targeted domains

C. Normal general social functioning and in daily life (ADL and IADL)

D. Do not fulfill the criteria for dementia

F. In drug development and research programs, should be specified:

a. aetiology

b. Neuroimaging

c. $\quad$ Clinical sub-type, e.g., impairment of memory only, an other predominant cognitive domain or multiple domains

\section{DeClaration}

Dr. Bouchard participated in dementia clinical trials with the following pharmaceutical companies: Pfizer, Eisai, Novartis, Janssen, Sanofi-Synthelabo, Neurochem and is consultant for Pfizer, Novartis, Janssen and Lundbeck. Dr. Bouchard received no financial support from any source for writing this manuscript.

\section{REFERENCES}

1. Organizing Committee, Canadian consensus conference on the Assessment of Dementia: the Canadian consensus. Can Med Assoc J. 1991; 144:851-3.

2. American Psychiatric Association, Committee on Nomenclature and Statistics. Diagnostic and statistical manual of mental disorders, 3rd edn, revised. Washington, DC: American Psychiatric Association (1987). 
3. American Psychiatric Association. Diagnostic and statistical manual of mental disorders. 4th ed. Washington, DC: American Psychiatric Association (1994).

4. American Psychiatric Association. Diagnostic and statistical manual of mental disorders. (IV-TR) . Washington, DC: American Psychiatric Association (2000).

5. Lopez OL, Becker JT, Klunk W, Saxton J, Hamilton RL, Kaufer DI, et al. Research evaluation and diagnosis of probable Alzheimer's disease over the last two decades: pt 1. Neurology. 2000;55: 1854-62.

6. Copeland MP, Daly E, Hines V, Mastromauro C, Zaitchik D, Gunther J, et al. Psychiatric Symptomatology and Prodromal Alzheimer's Disease. Alzheimer Dis Assoc Disord. 2003; 17:1-8.

7. Geerlings MI, Schmand B, Braam AW, Jonker C, Bouter LM, van Tilburg W. Depressive Symptoms and Risk of Alzheimer's Disease in more Highly Educated Older People. J Am Geriatr Soc. 2000;48:1092-7.

8. Lyketsos CG, Lopez O, Jones B, Fitzpatrick AL, Breitner J, DeKosky S. Prevalence of Neuropsychiatric Symptoms in Dementia and Mild Cognitive Impairment. JAMA. 2002;288:1475-83.

9. Knopman DS, DeKosky ST, Cummings JL, Chui H, Corey-Bloom J, Relkin N, et al. Practice parameter: Diagnosis of dementia (an evidence-based review); report of the Quality Standards Subcommittee of the American Academy of Neurology, Neurology. 2001; 56:1143-53.

10. McKhann G, Drachman D, Folstein M, Katzman R, Price D, Stadlan EM. Clinical diagnosis of Alzheimer's disease: Report of the NINCDS-ADRDA Work Group under the auspices of Department of Health and Human Services Task Force on Alzheimer's Disease. Neurology. 1984; 34: 939-44.

11. Holmes C, Cairns N, Lantos P, Mann A. Validity of current clinical criteria for Alzheimer's disease, vascular dementia and dementia with Lewy bodies. Br J Psychiatry. 1999;174:45-50.

12. Blacker D, Albert MS, Basset SS, Go RC, Harrell LE, Folstein MF, Reliability and validity of NINCDS-ADRDA criteria for Alzheimer's disease. The National Institute of Mental Health Genetics Initiative. Arch Neurol. 1994; 51:1198-204.

13. Neary D, Snowden JS, Gustafson L, Passant U, Stuss D, Black S, et al. Frontotemporal lobar degeneration: a consensus on clinical diagnostic criteria. Neurology. 1998;51:1546-54.

14. Feldman H, Levy AR, Hsiung GY, Peters KR, Donald A, Black SE, et al. A Canadian cohort study of cognitive impairment and related dementia (ACCORD): Study methods and baseline results. Neuroepidemiology. 2003; 22: 265-74.

15. Kertesz A, Munoz DG. Primary progressive aphasia and Pick complex. J Neurol Sci. 2003; 206: 97-107.

16. The Lund Manchester Groups. Clinical and neuropathological crirteria for Frontotemporal dementia. J Neurol Neurosurg Psychiatry. 1994 ; 57:416-8.

17. Miller BL, Ikonte C, Ponton M, Levy M, Boone K, Darby A, et al. A study of the Lund-Manchester research criteria for Frontotemporal dementia: clinical and single-photon emission CT correlations. Neurology. 1997; 46:937-42.

18. McKhann G M, Albert Marilyn S, Grossman M, Miller B, Dickson D, Trojanowski JQ. Clinical and Pathological Diagnosis of Frontotemporal Dementia: report of the Work Group on Frontotemporal Dementia and Pick's Disease. Arch Neurol. 2001;58:1803-9.

19. Kertesz A, Davidson W, McCabe P, Takagi K, Munoz D. Primary progressive aphasia: diagnosis, varieties, evolution. J Int Neuropsychol Soc. 2003; 9: 710-9.

20. Grosman M. Frontotemporal dementia: a review. J Int Neuropsychol Soc. 2002; 8: 566-83.

21. Gorno-Tempini ML, Dronkers NF, Rankin KP, Ogar JM, Phengrasamy L, Rosen HJ, et al. Cognition and anatomy in three variants of primary progressive aphasia. Ann Neurol. 2004; 55: 335-46.

22. McKeith IG, Dickson DW, Lowe J, Emre M, O’Brien JT, Feldman $\mathrm{H}$, et al. Diagnosis and management of dementia with Lewy bodies: Third report of the DLB consortium. Neurology. 2005; 65:1863-72.
23. Lopez OL, Litvan I, Catt KE, Stowe R, Klunk W, Kaufer DI, et al. Accuracy of four diagnostic criteria for the diagnosis of neurodegenerative dementias. Neurology. 1999;53:1292-9.

24. McKeith IG, Galasko D, Kosaka K, Perry EK, Dickson DW, Hansen LA, et al. Consensus guidelines for the clinical and pathologic diagnosis of dementia with Lewy bodies (DLB): report of the consortium on DLB international workshop. Neurology. 1996; 47: 1113-24.

25. McKeith IG, Perry EK, Perry RH. Report of the second dementia with Lewy body international workshop. Neurology. 1999;53:902-5.

26. Korszyn AD. Dementia in Parkinson's disease. J Neurol. 2001; 248 (Suppl 3): III/1-III/4.

27. Mayeux R, Denaro J, Hemenegildo N, Marder K, Tang MX, Cote LJ, et al. A population-based investigation of Parkinson's disease with and without dementia: relationship to age and gender. Arch Neurol. 1992;49:492-7.

28. Aarsland D, Tandberg E, Larsen JP, Cummings JL. Frequency of dementia in Parkinson's disease. Arch Neurol. 1996;53:538-42.

29. Aarsland D, Andersen K, Larsen JP, Lolk A, Nielsen H, KraghSorensen P. Risk of dementia in Parkinson's disease: a community-based, prospective study. Neurology. 2001;56:730-6.

30. Emre, M. Dementia associated with Parkinson's disease. THE Lancet Neurol. 2003; 2:229-37.

31. Boller F, Mizutani T, Roessmann U, Gambetti P. Parkinson Disease, Dementia, and Alzheimer's Disease: Clinicopathological Correlations. Ann Neurol. 1980;7:329-35.

32. Braak H, Rüb U, Jansen Steur ENH, Del Tredici K, de Vos RA. Cognitive status correlates with neuropathologic stage in Parkinson disease. Neurology. 2005;64:1404-10.

33. Leverenz JB, Fishel MA, Peskind ER, Montine TJ, Nochlin D, Steinbart E, et al. Lewy Body Pathology in Familial Alzheimer Disease. Arch Neurol. 2006:63:370-6.

34. Erisi MM, Wilcock GK, Morris JH. Neuropathological assessment of the lesions of significance in vascular dementia. J Neurol Neurosurg Psychiatry. 1997;63:749-53.

35. Tomlinson BE, Blessed G, Roth M. Observations on the brain of demented old people. J Neurol Sci. 1970;11:205-42.

36. Hansen, LA, Samuel, W. Criteria for Alzheimer's disease and the nosology of dementia with Lewy bodies. Neurology. 1997;48:126-32.

37. Hughes AJ, Daniel SE, Blankson, S, Lees AJ. A clinicopathologic study of 100 cases of Parkinson's disease. Arch Neurol. 1993:50:140-8.

38. McKeith I, Mintzer J, Aarsland D, Burn D, Chui H, CohenMansfield J, et al. Dementia with Lewy bodies. Lancet Neurology. 2004;3:19-28.

39. Rogers RD, Sahakian BJ, Hodges JR, Polkey CE, Kennard C, Robbins TW. Dissociating executive mechanisms of task control following frontal lobe and Parkinson's disease. Brain. 1998; 121:815-42.

40. Litvan I, Mohr E, Williams J, Gomez C, Chase TN. Differential memory and executive functions in demented patients with Parkinson's and Alzheimer's disease. J Neurol Neurosurg Psychiatry. 1991;54:25-9.

41. Pillon B, Boller F, Levy R, Dubois B. Cognitive deficits and dementia in Parkinson's disease. In: Boller F, Cappa S, eds. Handbook of Neuropsychology, 2edn. Amsterdam: Elsevier Science. 2001:311-71.

42. Knopman DS, Rocca WA, Cha RH, Eldman SD, Kokmen E. Incidence of vascular dementia in Rochester, Minn, 1985-1989. Arch Neurol. 2002;59:1605-10.

43. Lopez OL, Kuller LH, Becker JT, Jagust WJ, DeKosky ST, Fitzpatrick A, et al. Classification of vascular dementia in the Cardiovascular Health Study Cognition Study. Neurology. 2005; 64:1539-47.

44. Bowler JV. Vascular Cognitive impairment. J Neurol Neurosurg Psychiatry. 2005;76(Suppl V):v35-v44.

45. O’Brien JT, Erkinjuntti T, Reisberg B, Roman G, Sawada T, Pantoni L, et al. Vascular cognitive impairment. Lancet Neurology. 2003; 2:89-98. 
46. Roman G, Sachdev P, Royall DR, Bullock RA, Oogogozo JM, Lopez-Pousa S, et al. Vascular cognitive disorder: a new diagnostic category updating vascular cognitive impairment and vascular dementia . J Neurol Sci. 2004;226:81-7.

47. Sachdev P. Vascular cognitive disorder. Int J Geriatr Psychiatry. 1999; 14:402-3.

48. Erkinjuntti T, Roman G, Chui H. Diagnostic criteria. In : Erkinjuntti T, Gauthier S, eds. Vascular cognitive impairment. London: Martin Dunitz 2002:43-58.

49. Rockwood K, Black SE, Song X, Hogan DB, Gauthier S, Macknight $\mathrm{C}$, et al. Clinical and radiographic subtypes of vascular cognitive impairment in a clinic-based cohort study. J Neurol Sci. 2006; 240 (1-2):7-14.

50. Rockwood K, Bowler J, Erkinjuntti T, Hachinski V, Wallin A. Subtypes of vascular dementia. Alzheimer Dis Assoc Disord. 1999; 13 Suppl 3 :S59-65.

51. World Health Organisation. The ICD-10 Classification of Mental and Behavioural Disorders: Clinical Descriptions and diagnostic Guidelines. Geneva: World Health Organisation. 1992:50-1.

52. Chui HC, Victoroff JI, Margolin D, Jagust W, Shankle R, Katzman R. Criteria for the diagnosis of ischemic vascular dementia proposed by the State of California Alzheimer's Disease Diagnostic and Treatment Centers. Neurology. 1992;42:473-80.

53. Roman G, Tatemichi TK, Erkinjuntti T, the NINDS-AIREN Workgroup. Vascular dementia: diagnostic criteria for research studies. Report of the NINDS-AIREN International workshop. Neurology. 1993; 43: 250-60.

54. Rosen WG, Terry RD, Fuld PA, Katzman R, Peck A. Pathological verification of ischemic score in differentiation of dementias. Ann Neurol. 1980; 7:486-8.

55. Pantoni L, Garcia JH, Brown GG. Vascular pathology in three cases of progressive cognitive deterioration. J Neurol Sci. 1996;135:131-9.

56. Hulette, C, Nochlin, D, McKeel DW, Morris JC, Mirra SS, Sumi $\mathrm{SM}$, et al. Clinical-neuropathologic findings in multi-infarct dementia: a report of six autopsied cases. Neurology. 1997;48:668-72.

57. Wettering T, Kanitz RD, Borgis KJ. Comparison of different diagnostic criteria for vascular dementia (ADDTC, DSM-IV, ICD-10, NINDS-AIREN). Stroke. 1996;27:30-6.

58. Crook T, Bartus, RT, Ferris SH, Whitehouse P, Cohen GD, Gershon S. Age-associate memory impairment: proposed diagnostic criteria and measures of clinical changes: report of the National Institute of Mental Health Work Group. Dev Neuropsychol. 1986; 2:261-76.

59. Ebly EM, Hogan DB, Parhad I. Cognitive impairment in the non demented elderly. Results from the Canadian Study of Health and Aging (CSHA), Arch Neurol. 1995; 52:612-9.

60. Levy R. Aging-Associated cognitive Decline. Int Psychogeriatr. 1994; 6:63-68
61. Feldman HH, Jacova, C. Mild Cognitive impairment. Am J Geriatr Psychiatry. 2005; 13:645-55.

62. Saxton J, Lopez OL, Ratcliff G, Dulberg C, Fried LP, Carlson MC. Preclinical Alzheimer disease: Neuropsychological test performance 1.5 to 8 years prior to onset. Neurology. 2004;63:2341-47.

63. Morris JC, Storandt M, Miller JP, Mckeel DW, Price JL, Rubin EH. Mild cognitive impairment represents early-stage Alzheimer's disease. Arch Neurol. 2001;58:397-405.

64. Petersen RC, Smith GE, Waring SC, Ivnik RJ, Tangalos EG, Kokmen E. Mild cognitive impairment: clinical characterization and outcome. Arch Neurol. 1999;56:303-8.

65. Schröder J, Kratz B, Pantel J, Minnemann E, Lehr U, Sauer H. Prevalence of mild cognitive impairment in an elderly community sample. J Neural Transm. 1998 (Suppl.): 54: 51-9.

66. Loewenstein DA, Acevedo A, Argon J, Issacson R, Strauman S, Crocco E, et al. Cognitive profiles in Alzheimer's disease and in mild cognitive impairment of different etiologies. Dement Geriatr Cogn Disord. 2006;21(5-6):309-15.

67. Ribeiro F, de Mendonca A, Guerreiro M. Mild cognitive impairment: deficits in cognitive domains other than memory. Dement Geriatr Cogn Disord. 2006;21(5-6):284-90.

68. Petersen RC, Doody R, Kurz A, Mohs RC, Morris JC, Rabins PV, et al. Current concepts in mild cognitive impairment. Arch Neurol. 2001; 58:1985-92.

69. Grundman M., Petersen RC, Morris JC, Ferris S, Sano M, Farlow MR, et al. Rate of dementia of Alzheimer type (DAT) in subjects with mild cognitive impairment: the Alzheimer's Disease Cooperative Study (Abstract). Neurology. 1996; 46:A403.

70. Petersen RC, Parisi JE, Dickson DW, Johnson KA, Knopman DS, Boeve BF, et al. Neuropathological features of amnestic mild cognitive impairment. Arch Neurol.2006; 63:665-72.

71. Jicha GA, Parisi JE, Dickson DW, Johnson K, Cha R, Ivnik RJ, et al. Neuropathological outcome of mild cognitive impairment following progression to clinical Dementia. Arch Neurol. 2006;63:674-81. 